Article

\title{
Catalyst-Free Biodiesel Production Methods: A Comparative Technical and Environmental Evaluation
}

\author{
Oseweuba Valentine Okoro ${ }^{1}$ (D), Zhifa Sun ${ }^{1, *}$ and John Birch ${ }^{2}$ \\ 1 Department of Physics, University of Otago, P.O. Box 56, Dunedin 9054, New Zealand; \\ okoos343@student.otago.ac.nz \\ 2 Department of Food Science, University of Otago, P.O. Box 56, Dunedin 9054, New Zealand; \\ john.birch@otago.ac.nz \\ * Correspondence: zhifa.sun@otago.ac.nz; Tel.: +64-3-479-7812
}

Received: 25 October 2017; Accepted: 3 January 2018; Published: 8 January 2018

\begin{abstract}
In response to existing global focus on improved biodiesel production methods via highly efficient catalyst-free high temperature and high pressure technologies, this study considered the comparative study of catalyst-free technologies for biodiesel production as an important research area. In this study, therefore, catalyst-free integrated subcritical lipid hydrolysis and supercritical esterification and catalyst-free one step supercritical transesterification processes for biodiesel production have been evaluated via undertaking straight forward comparative energetic and environmental assessments. Energetic comparisons were undertaken after heat integration was performed since energy reduction has favourable effects on the environmental performance of chemical processes. The study confirmed that both processes are capable of producing biodiesel of high purity with catalyst-free integrated subcritical lipid hydrolysis and supercritical esterification characterised by a greater energy cost than catalyst-free one step supercritical transesterification processes for an equivalent biodiesel productivity potential. It was demonstrated that a one-step supercritical transesterification for biodiesel production presents an energetically more favourable catalyst-free biodiesel production pathway compared to the integrated subcritical lipid hydrolysis and supercritical esterification biodiesel production process. The one-step supercritical transesterification for biodiesel production was also shown to present an improved environmental performance compared to the integrated subcritical lipid hydrolysis and supercritical esterification biodiesel production process. This is because of the higher potential environment impact calculated for the integrated subcritical lipid hydrolysis and supercritical esterification compared to the potential environment impact calculated for the supercritical transesterification process, when all material and energy flows are considered. Finally the major contributors to the environmental outcomes of both processes were also clearly elucidated.
\end{abstract}

Keywords: waste reduction algorithm; potential environmental impact; catalyst-free biodiesel production; heat integration

\section{Introduction}

In line with the global efforts to encourage a shift from fossil fuels to renewable and cleaner biofuels, many studies have been undertaken to develop sustainable liquid fuel alternatives. These studies have resulted in the identification of biodiesel as a sustainable and environmentally benign fuel alternative that will aid in reducing peak global temperatures via the reduction in the volumes of greenhouse gas emissions such as $\mathrm{CO}_{2}, \mathrm{NO}_{\mathrm{x}}$ and $\mathrm{SO}_{2}$ [1]. This recognised importance of biodiesel as a renewable fuel has resulted in extensive work in the area of biodiesel research. Some of 
these studies include the exploration of alternative biodiesel production pathways such as catalyst-free subcritical and supercritical biodiesel production processes [2,3] for enhanced biodiesel yields in short reaction times, the use of unconventional biodiesel feedstocks such as meat processing DAF sludge [1] and sewage sludge [4] as alternative lipid sources to improve economic performances and the modification of existing biodiesel production processes such as application of in-situ approaches to enhance biodiesel productivity [5]. Current investigations however highlight scientific interest in catalyst-free biodiesel production processes due to reduced reaction times $(<10 \mathrm{~min})$ and high percentage conversions $(>95 \%)$ typically recorded in experimental work $[2,6,7]$. Conventional catalyst-free biodiesel production processes are essentially transesterification reactions occurring under supercritical conditions of the reacting alcohols. Under such supercritical conditions the reacting alcohols usually exist in their supercritical state since the reacting conditions are at temperatures higher than the critical temperatures, $238.85^{\circ} \mathrm{C}$ and $241{ }^{\circ} \mathrm{C}$, of methanol and ethanol respectively and pressures higher than the critical pressures, $8.1 \mathrm{MPa}$ and $6.41 \mathrm{MPa}$, of methanol and ethanol respectively $[8,9]$.

The significantly improved reaction rate reported in such supercritical transesterification reactions is due to the reduction in the strength of the intermolecular hydrogen bonds that exist between the alcohol molecules, leading to a significant reduction in the alcohol dielectric constant [10]. Polarity reductions due to the weakening of the hydrogen bonds will enhance nucleophilic attack on the carbonyl carbon by the alcohol, thus rendering the use of a catalyst unnecessary [10]. Furthermore, the reduced dielectric constant of the alcohol will make the originally polar alcohol a more suitable solvent for the solvation of the non-polar lipids, thereby enabling the generation of a single phase lipid-alcohol mixture under supercritical conditions [10]. The existence of the reactants in a single phase also substantially enhances the alcoholysis reaction rate since possible mass transfer inhibitions between the reacting species are reduced [11]. Crucially, although high biodiesel yields were reported when direct supercritical transesterification (DST) processes are undertaken, these processes are characterised by very large energy consumption and high chemical cost $[2,12,13]$. The large energy consumption is due to the imposition of conditions of high temperature $\left(350^{\circ} \mathrm{C}\right)$, high pressures $(>20 \mathrm{MPa})$ and the high chemical cost is due to the requirement of large masses of the alcohol reactant, for instance DST biodiesel production processes utilising methanol as the alcohol reactant will require a methanol to oil mole feed ratio greater than 40:1 [2,14].

Furthermore, recent studies have also established that the imposition of such high temperature conditions on supercritical transesterification reaction systems will lead to the degradation of the biodiesel product thus reducing biodiesel yield [15]. The degradation of the fatty acid methyl ester (FAME) product typically occurs via radical chain scission with previous studies demonstrating that the degradation of methyl stearate and methyl oleate to shorter chain 1-alkenes and alkanes respectively will occur at reaction temperatures greater than $260^{\circ} \mathrm{C}[6,15,16]$. To circumvent the need for high energy input and the need for large masses of methanol chemical inputs, some studies have suggested the viability of the alternative utilisation of an integrated subcritical lipid hydrolysis and supercritical esterification (ISHSE) process. This is because the ISHSE process, which integrates an initial subcritical lipid hydrolysis with a supercritical esterification reaction requires a lower molar methanol to oil ratio of $20: 1$, lower reaction temperatures ranging from $250{ }^{\circ} \mathrm{C}$ to $270{ }^{\circ} \mathrm{C}$ and lower pressures ranging from $7 \mathrm{MPa}$ to $8.1 \mathrm{MPa}$, compared to the reaction conditions of alternative catalyst-free DST biodiesel production processes $[6,17]$. Remarkably however the previous studies undertaken by Kusdiana and Saka, [17] and Jin et al. [6] did not consider the potential effects of integrating an initial subcritical lipid hydrolysis process with the supercritical esterification of the generated fatty acids on the efficiency of energy utilization, environmental impacts and the effects of the associated waste streams of the production process.

It is important at this juncture to state that the simulation studies of the high temperature and pressure biodiesel production processes does not constitute an entirely new research area with previous studies considering the technical feasibility of high pressure biodiesel production processes [18] and 
the energetic cost of the high pressure biodiesel production processes [19]. However at present there is no investigation focusing on the comparative assessment of these highlighted high temperature and pressure biodiesel production processes. Clearly a comparative assessment of overall energetic performance, and environmental impacts related to emissions to air, land and water is overdue. This study is therefore interested in the undertaking a comparative assessment of the alternative catalyst-free biodiesel production pathways with particular emphasis on the energetics and the environmental impacts of the alternative biodiesel production processes.

\section{Materials and Methods}

\subsection{Analysis Tools}

In this paper, an ASPEN plus version 10.0 (Aspen Technology Inc., Cambridge, MA, USA) process simulator is utilised to simulate the ISHSE process and DST process. This simulator is selected since it enables the generation of accurate mass and energy balance data in a timely fashion. This simulation software also facilitates the computation of the flow rates, compositions, and physical characteristics of the input and output streams which will constitute the basis for subsequent energetic and environmental performance assessments. The processes of DST and ISHSE for biodiesel production to be investigated are illustrated in Figures 1 and 2 respectively. In the alternative pathways investigated, the biodiesel production capacity is fixed to a production capacity of approximately $6120 \mathrm{t}$ per $\mathrm{y}$ with the plants operating for $7200 \mathrm{~h}$ per $\mathrm{y}$. In Figures 1 and 2, the 'dashed' blocks represent the overall processes and the solid blocks denote the individual processes. Figure 1 shows that the overall DST biodiesel production process involves a supercritical transesterification reaction of triglycerides in the presence of methanol at a temperature of $280{ }^{\circ} \mathrm{C}$ and a pressure $28 \mathrm{MPa}$. At the conclusion of the transesterification reaction the excess and unreacted methanol is recovered via vaporisation from the FAME and glycerol products. Further purification of the FAME product to remove the glycerol and any remaining methanol impurity is subsequently achieved via the distillation process shown in Figure 1 using a distillation column. Figure 2 shows that the overall ISHSE biodiesel production process involves an initial water-subcritical hydrolysis of triglycerides at a temperature of $270{ }^{\circ} \mathrm{C}$ and a pressure $7 \mathrm{MPa}$ and then the generated fatty acids are separated via decantation, with residual polar aqueous phase containing glycerol and water hydrolysis being left. The separated fatty acids are esterified in the presence of methanol under supercritical conditions of $250{ }^{\circ} \mathrm{C}$ and $8 \mathrm{MPa}$ of methanol. At the conclusion of the supercritical esterification reaction, the FAME product is purified by separating the FAMEs from the unreacted methanol and water via vaporisation of methanol and water impurities. Recovery of methanol from the residual methanol-water mixture is undertaken using the distillation columns as shown in Figure 2. The following mass and energy balance equations at steady state were used and solved using ASPEN plus for each of the individual processes of the DST and ISHSE biodiesel production processes shown in Figures 1 and 2,

$$
\begin{gathered}
\sum_{i=1}^{n} \dot{m}_{\text {in }}=\sum_{i=1}^{n} \dot{m}_{\text {out }} \\
\dot{Q}=\left[\sum_{i=1}^{n} \dot{m}_{i} h_{i}\right]_{\text {out }}-\left[\sum_{i=1}^{n} \dot{m}_{i} h_{i}\right]_{\text {in }}+\dot{W}
\end{gathered}
$$

where, $\dot{Q}$ is the net heat transfer flow rate in $\mathrm{kJ} / \mathrm{s}$ into the system in the control volume of the individual process, per $\mathrm{s} ; h_{i}$ is the specific enthalpy of the $i$ th stream, in $\mathrm{kJ} / \mathrm{kg}$; $\dot{W}$ is the rate of net work done by the system in the control volume of the individual process in $\mathrm{kJ} / \mathrm{s}$; and $\dot{m}$ is the mass flow rate of the ith stream, in $\mathrm{kg} / \mathrm{s}$.

To minimise the cooling and heating duties of both high temperature and high pressure biodiesel production processes, Aspen Energy Analyser ${ }^{\circledR}$ (Aspen Technology Inc., Cambridge, MA, USA) is used to perform heat integration and to design a possible heat exchanger network based on classic pinch analysis 
methods. These pinch analysis methods incorporate the assessment of heat flow rate inequalities and stream splitting rules via tick-off heuristics [20]. In utilising Aspen Energy Analyser ${ }^{\circledR}$ for the reduction of heating and the cooling duties, the procedure proposed by Sadhukha et al. [21] is utilised. Necessary thermodynamic data highlighting the supply temperature and target temperature of relevant streams are extracted from simulation output sheet generated by ASPEN plus. Using these data the composite curve is constructed to aid in the determination of the minimum energy consumption target since the overlap of heat availability (hot composite curve) and the heat requirement (cold composite curve) provides an indication of the maximum possible process heat recovery [22]. The determination of the possible heat recovery enables the estimation of the remaining heating requirement (called the minimum hot $\mathrm{Q}(\mathrm{H})_{\min }$ ) and cooling requirements (called the minimum cold $\mathrm{Q}(\mathrm{C})_{\min }$ ). Further optimisation of heat exchanger design to minimise economic cost are outside the scope of this research as process optimisation approaches are not considered in this study. For simplicity we have adopted the minimum allowable temperature difference $\left(\Delta \mathrm{T}_{\mathrm{min}}\right)$ at 'pinch point', in a heat exchanger to be $10 \mathrm{~K}$ [23]. All calculations are performed using the Aspen Energy Analyser and results reported directly. Finally, the heat exchanger network is fully solved using the Aspen Energy Analyser ${ }^{\circledR}$ with all the process streams satisfied based on the adopted minimum allowable temperature difference.

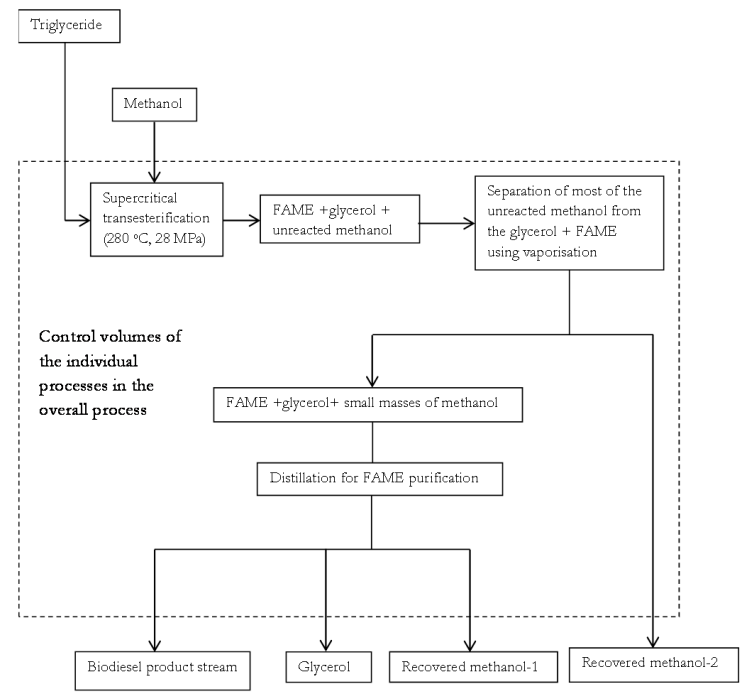

Figure 1. Block flow diagram for the DST biodiesel production process.

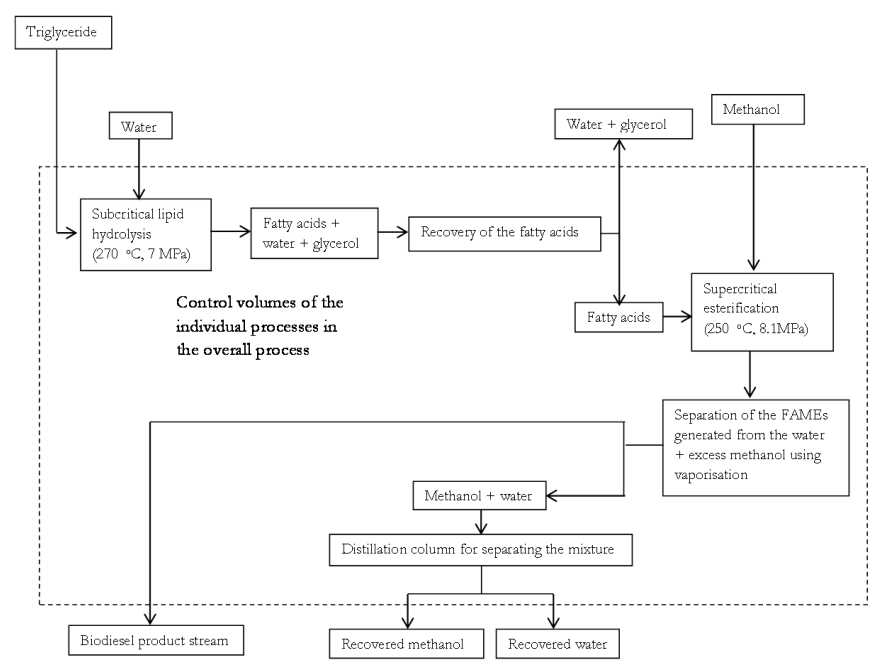

Figure 2. Block flow diagram for the ISHSE biodiesel production process. 


\subsubsection{Calculation of Physical and Thermodynamic Properties}

The NRTL-Redlich-Kwong property method in ASPEN plus was utilised in predicting the properties of the chemical species in the liquid and vapour phases. This is because the NRTL activity coefficient model was shown to be sufficient in predicting the vapour-liquid equilibria of chemical species under moderate conditions while the Redlich-Kwong model adequately predicts the vapour-liquid equilibria of the chemical species under supercritical and subcritical conditions [24]. The triglyceride molecule in the reaction was modelled as triolein in this paper, in accordance with the experimental data of subcritical lipid hydrolysis of triolein and the kinetic models of the supercritical esterification of oleic acid and supercritical transesterification of triolein for producing methyl oleate $[6,25,26]$. This methyl oleate product sufficiently models biodiesel since its major fuel properties satisfy existing European biodiesel standard (EN 14214) and American biodiesel standard (ASTM D 6751) as presented in Table 1.

Table 1. Major fuel properties of the methyl oleate model biodiesel product compared to existing standards.

\begin{tabular}{cccc}
\hline Fuel Property of Methyl Oleate & Value & EN 14214 & ASTM D6751 $^{\mathbf{f}}$ \\
\hline Higher heating value $(\mathrm{kJ} / \mathrm{kg})$ & $39.91^{\mathrm{a}}$ & $>35$ & NS \\
Density $\left(\mathrm{kg} / \mathrm{m}^{3}\right.$ at $\left.15^{\circ} \mathrm{C}\right)$ & $877.46^{\mathrm{b}}$ & $860 \leq \rho \leq 900$ & NS \\
Kinematic viscosity $\left(\mathrm{mm}^{2} / \mathrm{s}\right.$ at $\left.40^{\circ} \mathrm{C}\right)$ & $4.51^{\mathrm{c}}$ & $3.5 \leq v \leq 5.0$ & $1.9 \leq v \leq 6.0$ \\
Cetane number & $59.3^{\mathrm{c}}$ & $\geq 51$ & $\geq 47$ \\
Iodine index & $84.4^{\mathrm{d}}$ & $\leq 120$ & NS \\
\hline
\end{tabular}

${ }^{\mathrm{a}}\left[27,^{\mathrm{b}}[28]^{\mathrm{c}}[29]^{\mathrm{d}}[30]^{\mathrm{e}}[31]^{\mathrm{f}}[32]\right.$.

In this work, the values of the critical temperature, critical pressure and acentric factor for triolein calculated by Tang et al. [33] were used to define triolein in the component database of the ASPEN plus. The boiling temperature of triolein was specified to be $548.3^{\circ} \mathrm{C}[34]$ rather than $846^{\circ} \mathrm{C}$ available in ASPEN plus since previous studies have established that the boiling point temperature for triolein present in the ASPEN plus database is overestimated [34].

The vapour pressure was calculated as follows [35],

$$
\ln p_{v p}=6.596-\frac{5407.3}{T}
$$

The thermodynamic properties of other chemicals such as glycerol, methanol, oleic acids, methyl oleate and water were obtained from the component database of the ASPEN plus. For simplicity perfect mixing of the reacting species has also been assumed.

\subsubsection{Kinetic Modelling of Subcritical Lipid Hydrolysis and Supercritical Fatty Acid Esterification}

In modelling the subcritical lipid hydrolysis reaction the FA yield data reported by Minami and Saka [25] for subcritical triglyceride (TAG) hydrolysis of lipids undertaken at temperatures ranging from $250{ }^{\circ} \mathrm{C}$ to $320^{\circ} \mathrm{C}$ and pressures ranging from $7 \mathrm{MPa}$ to $20 \mathrm{MPa}$ in a batch-wise reactor were analysed. In the experiments by Minami and Saka, excess water was utilised such that the molar ratio of water to TAG was 53.8:1 and the initial concentrations of the TAG and water were $0.56 \mathrm{~mole} / \mathrm{L}$ and 27.75 mole/L, respectively. The experimental data obtained by Minami and Saka have been presented in Figure 3. 


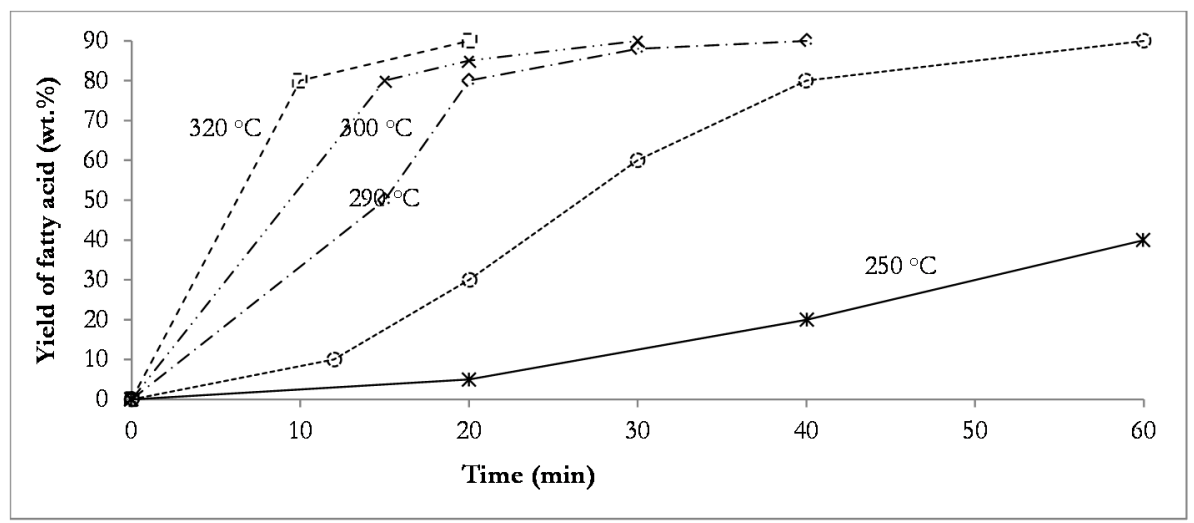

Figure 3. Lipid hydrolysis in supercritical water (adapted from Minami and Saka [25]).

The subcritical TAG hydrolysis was modelled as occurring according to the following reaction equation,

$$
\mathrm{TAG}+3 \mathrm{H}_{2} \mathrm{O} \leftrightarrow \mathrm{Gly}+3 \mathrm{FA}
$$

where, Gly represents the glycerol and FA represents the fatty acid.

This study recognises that TAG hydrolysis reaction have also been reported as occuring via a stage wise pathway under moderate reaction conditions with the intermediate molecules of diglyceride and mono glyceride shown to be formed during different stages of the process. Crucially however, under subcritical conditions such intermediate steps can be ignored with authors such as Kocsisová et al. [36] and Sturzenegge and Stum [37] demonstrating experimentally the validity of an alternative pseudo-homogenous First order irreversible kinetic relation provided the conditions of excess water and subcritical reaction conditions are maintained. According to these authors under conditions of excess moisture the rate of the TAG hydrolysis under subcritical conditions can be presented as follows,

$$
r_{h y}=-\frac{d C_{\mathrm{TAG}}}{d t} \cong k_{h y} C_{\mathrm{TAG}}
$$

Such that the integration of Equation (5) provides a relationship between the fractional conversion, $X$, of the TAG, as follows,

$$
-\operatorname{Ln}\left[\frac{C_{\mathrm{TAG}, f}}{C_{\mathrm{TAG}, \mathrm{o}}}\right]=-\left[\frac{C_{\mathrm{TAG}, \mathrm{o}}(1-X)}{C_{\mathrm{TAG}, \mathrm{o}}}\right]=k_{h y} t
$$

or,

$$
\operatorname{Ln}[1-X]=-k_{h y} t
$$

with the reaction rate constant $\left(k_{h y}\right)$ expressed by the following relation,

$$
k_{h y}=A_{h y} e^{-\left[\frac{E_{h y}}{R T}\right]}
$$

In Equation (8), $k_{h y}, A_{h y}, E_{h y}, R$ and $T$ represent the approximate overall rate constant, in $\mathrm{s}^{-1}$; pre-exponential constant, in $\mathrm{s}^{-1}$; activation energy, in $\mathrm{kJ} / \mathrm{kmol}$, universal gas constant, in $8.314 \mathrm{~kJ} / \mathrm{kmol} \cdot \mathrm{K}$ and temperature in $K$, respectively.

Thus, a plot of Ln $[1-X]$ against time is a straight line and the slope of the line equal to value of $-k_{h y}$ for a set of experimental data.

Using the data shown in Figure 3, we have evaluated the conversion factor at different temperatures and the results are in Figure 4. Applying Equation (7), fitted straight lines representing the relations between the conversion factor and reacting time at different temperatures are also presented in Figure 4. From Figure 4, it can be seen that all the straight lines have a correlation coefficient $\left(R^{2}\right)$ 
value greater than 0.9 . Since the $R^{2}$ values determined are all greater than the accepted minimum $R^{2}$ value of 0.7 specified in modelling work [38], it can be suggested that the kinetic relationship represented by the linear plot is sufficient to predict the yield of FAs generated during subcritical hydrolysis and can be employed to achieve the aims of this paper. This implies therefore that the kinetic parameters $\left(A_{h y}\right.$ and $\left.E_{h y}\right)$, can be easily estimated by plotting Ln $k_{h y}$, which is obtained from the graph slopes in Figure 4 against $1 / T$ such that the slope and the intercept will give the $E_{h y} / R$ and the $A_{h y}$ respectively. The plot of Ln $k_{h y}$ against $1 / T$ for temperatures ranging from $250{ }^{\circ} \mathrm{C}$ to $320{ }^{\circ} \mathrm{C}$ has therefore been presented in Figure 5.

Figure 5 shows that the relationship between $k_{h y}$ and $T$ is as follows,

$$
\operatorname{Ln} k_{h y}=-\frac{10,599}{T}+12.039
$$

or

$$
k_{h y}=169,227.6 e^{-\left[\frac{88,120.1}{R T}\right]}
$$

The kinetic relation presented in Equation (10) was therefore utilised in modelling the subcritical hydrolysis of TAGs in the present study.

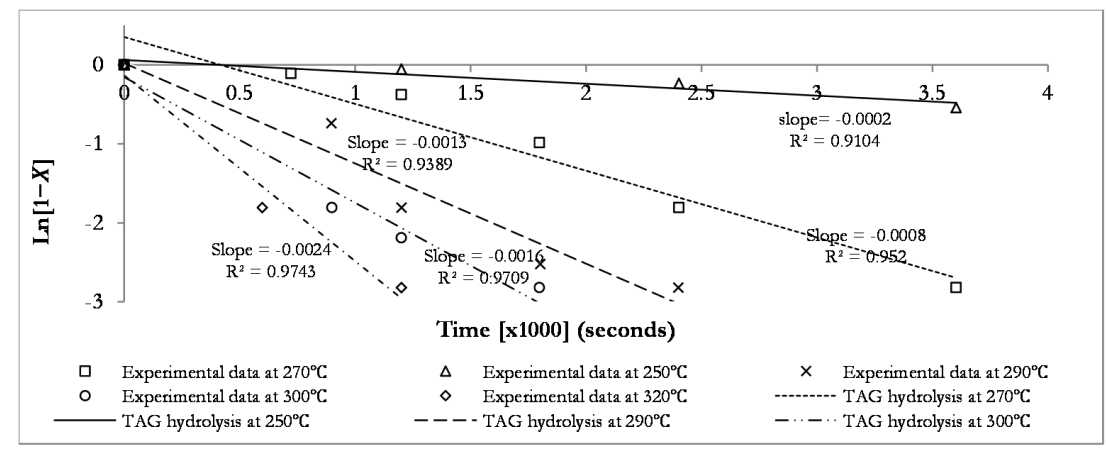

Figure 4. Relations between the conversion factor and time at different operating temperatures. Points: data based on the experimental data obtained by Minami and Saka [25]. Lines: fitted lines using Equation (7).

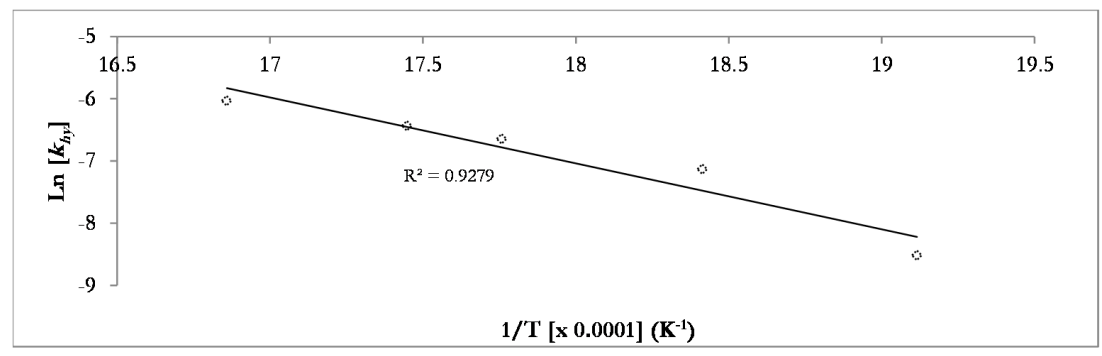

Figure 5. The relation between $k_{h y}$ and $T$ for subcritical hydrolysis of TAG at temperatures ranging from $250^{\circ} \mathrm{C}$ to $320^{\circ} \mathrm{C}$.

The supercritical esterification of the FAs generated from the subcritical hydrolysis of the TAG in the ISHSE process is expressed by the following chemical reaction,

$$
\mathrm{FA}+\mathrm{MeOH} \rightarrow \mathrm{FAME}+\mathrm{H}_{2} \mathrm{O}
$$

In this paper, the supercritical esterification of FAs was modelled as occurring via irreversible First order kinetics, following the experimental analysis by Jin et al. [6] as follows, 


$$
r_{s c}=-\frac{d C_{\mathrm{FA}}}{d t} \cong k_{s c} C_{\mathrm{FA}}
$$

Possible side reactions which are associated with the thermal cracking, isomerisation and decarboxylation of FAMEs will not be considered in this study since the mechanisms and reaction equations of these side reactions are presently unknown [39].

The rate constant of the supercritical esterification reaction $\left(k_{s c}\right)$ at the operating temperature, molar ratio of methanol to FA and pressure of $260^{\circ} \mathrm{C}, 20: 1$ and $8.1 \mathrm{MPa}$ was reported, and is given by [6],

$$
k_{s c}=0.136 e^{-\left[\frac{21,980}{R T}\right]}
$$

where $k_{h y}$ is the rate constant of supercritical esterification in $\mathrm{s}^{-1}$, the constant number 0.136 is the pre-exponential constant in $\mathrm{s}^{-1}$, the constant value 21,980 is the activation energy in $\mathrm{kJ} / \mathrm{kmol}, R$ is the universal gas constant, $8.314 \mathrm{~kJ} / \mathrm{kmol} \cdot \mathrm{K}$ and $T$ is the temperature in $K$.

The supercritical transesterification of TAGs using methanol in the DST process has also been modelled in this paper as an irreversible a first order reaction, following the experimental analysis undertaken by He et al. [26] as follows,

$$
\mathrm{TAG}+3 \mathrm{MeOH} \rightarrow 3 \mathrm{FAME}+\text { Glycerol }
$$

such that,

$$
r_{s p}=-\frac{d C_{\mathrm{TAG}}}{d t} \cong k_{s p} C_{\mathrm{TAG}}
$$

The rate constant of the supercritical transesterification reaction at the operating temperature, molar ratio of methanol to TAG and pressure of $280^{\circ} \mathrm{C}, 42: 1$ and $28 \mathrm{MPa}$ was reported as follows [26],

$$
k_{s p}=141.796 e^{-\left[\frac{56,000}{R T}\right]}
$$

where $k_{s p}$ is the rate constant of supercritical transesterification, in $\mathrm{s}^{-1}$, the constant value 141.796 is the pre-exponential constant, in $\mathrm{s}^{-1}$, the constant value 56,000 is the activation energy, in $\mathrm{kJ} / \mathrm{kmole}$, $R$ is the universal gas constant, $8.314 \mathrm{~kJ} / \mathrm{kmole}$. $K$ and $T$ is the temperature, in $K$.

\subsubsection{Potential Environmental Impact Assessment}

The potential environmental impacts (PEIs) of the alternative catalyst-free biodiesel production processes were investigated using a comprehensive environmental impact assessment (EIA) tool, the waste reduction (WAR) algorithm (WAR version 1.0.17, United States Environmental Protection Agency, Washington, DC, USA). The WAR impact assessment tool has been identified as the preferred impact assessment tool when it is necessary to compare anticipated environmental impacts associated with only the chemical production processing facility [40] and has been used extensively in previous work [41,42]. Considering that the objectives of this study does not encompass the determination of suitable waste minimisation opportunities [43], assessment of environmental risk (environmental impact minimization and the environmental fate and risk assessment tool) [44] or the assessment of impacts associated with raw material acquisition, product distribution or product recycle (Ecoindicator-99 for life cycle analysis tool) [45], the utilisation of these aforementioned alternative environmental assessment tools is pointless. The sufficiency of the utilisation of the WAR algorithm in achieving the research objectives is therefore justified.

WAR algorithm is a powerful environmental impact assessment tool that utilises the mass balance data describing the flow rate and composition of the streams entering into and exiting a chemical process and energy balance data describing the rate of energy consumption from fossil-based sources to calculate the potential impact of the a process if the chemicals utilised in the process are directly emitted to the environment [45]. This environmental impact assessment tool was developed in response to 
the need for rapid assessments of environmental impacts during the conceptual and design stages of manufacturing processes [46]. The WAR algorithm enables the determination of the conceptual PEI of a process via an approach analogous to the classic mass or energy balances, since the theoretical PEI of an a chemical process is assumed to be conserved. Therefore for steady state processes the PEI balance of a chemical process is as follows [45],

$$
\dot{I}_{\text {in }}^{c p}+\dot{I}_{\text {in }}^{e p}-\dot{I}_{o u t}^{c p}-\dot{I}_{o u t}^{e p}-\dot{I}_{w e}^{c p}-\dot{I}_{w e}^{e p}+\dot{I}_{g e n}=0
$$

Implying that the rate of PEI generation $\left(\dot{I}_{g e n}\right)$ is as follows,

$$
\dot{I}_{g e n}=-\left[\dot{I}_{\text {in }}^{c p}+\dot{I}_{\text {in }}^{e p}-\dot{I}_{\text {out }}^{c p}-\dot{I}_{\text {out }}^{e p}-\dot{I}_{w e}^{c p}-\dot{I}_{w e}^{e p}\right]
$$

where according to Young and Cabezas [45],

$$
\begin{gathered}
\dot{I}_{\text {out }}^{c p}=\sum_{i}^{c p} \dot{I}_{i}^{\text {out }}=\sum_{i}^{c p} \dot{M}_{i}^{\text {out }} \sum_{k} x_{i} \phi_{k} \\
\dot{I}_{\text {in }}^{c p}=\sum_{i}^{c p} \dot{I}_{i}^{i n}=\sum_{i}^{c p} \dot{M}_{i}^{\text {in }} \sum_{k} x_{i} \phi_{k} \\
\dot{I}_{\text {out }}^{e p}=\sum_{i}^{e p-g} \dot{M}_{i}^{\text {out }} \sum_{k} x_{k i} \phi_{k} \\
\dot{I}_{\text {in }}^{e p}=\sum_{i}^{e p-g} \dot{M}_{i}^{\text {in }} \sum_{k} x_{k i} \phi_{k} \\
\dot{I}_{\text {we }}^{e p}=\sum_{i}^{e p} \dot{E}_{i}^{e p} x_{w e} \phi_{k} \\
\dot{I}_{\text {we }}^{c p}=\sum_{i}^{c p} \dot{E}_{i}^{c p} x_{w e} \phi_{k}
\end{gathered}
$$

In these Eqns., $\dot{I}_{i n}^{c p}$ and $\dot{I}_{o u t}^{c p}$ are the rate of PEIs into and out of a system due to chemical interactions within the system respectively; $\dot{I}_{\text {out }}^{e p}$ and $\dot{I}_{i n}^{e p}$ are the rate of PEI out and into a system due to energy generation processes within the system respectively; $\dot{I}_{w e}^{e p}$ and $\dot{I}_{w e}^{c p}$ are the PEI out of a system as a result of the release of waste energy due to energy generation and chemical processes within a system respectively; $\dot{E}_{i}^{c p}$ and $\dot{E}_{i}^{e p}$ are the rate of waste energy emission from the chemical process and energy generation process. Typically, in the context of the WAR algorithm, the $\dot{I}_{w e}^{e p}$ and $\dot{I}_{w e}^{c p}$ terms are considered as negligible since chemical process plants do not produce significant 'unwanted' energy into the environment [45]. Furthermore, for chemical plants the potential environmental impact associated with the emission of mass such as the spills of large mass of toxic chemicals or large masses of gaseous pollutants is usually much greater than that associated with the emission of energy such as rise in the temperature of the surrounding environment, Young and Cabezas [45] also emphasize that the rate of PEI out of a system as a result of energy generation processes $\left(I_{\text {out }}^{e p}\right)$ are largely due to the generation of masses of gaseous pollutants such as $\mathrm{SO}_{2}, \mathrm{NO}_{\mathrm{x}}, \mathrm{CO}$ and $\mathrm{CO}_{2}$ which are a consequence of the combustion of solid, liquid and gaseous fuels. is the mass flow rate of stream $i$ output stream, $\dot{M}_{i}^{i n}$ is the mass flow rate of stream $i$ input stream, $x_{k i}$ is the mass fraction of component $k$ in stream $i$ and $\emptyset_{k}$ is the potential environmental impact due to component $k$. The parameter, $\emptyset_{k}$, was determined by 
summing the specific potential environmental impact of component $k$ over all of the possible impact categories $l$ as follows [45],

$$
\psi_{k}=\sum_{l} \alpha_{i} \phi_{k l}^{s}
$$

In Equation (25), $\alpha_{i}$ represents the relative weighting factor of impact categories, $l$ and is indicative of the importance of each impact category to the analysis. In this study, however all impact categories were considered equally significant. The approach of considering the impact categories equally significant constitutes the accepted approach when the case studies being assessed have no specific site in mind $[41,42,45]$. The impact categories were classified largely based on extensive studies undertaken by Heijungs et al. [47]. The potential environmental impacts of each chemical utilised in the chemical process were obtained from a chemical database similar to the database present in the ChemCad 4.0 software (ChemCad, Houston, TX, USA). The impact categories $l$ embeded in the WAR algorithm and the measure of impact category are presented in Table 2. Normalisation of the impact scores of the potential environmental impact due to component $k$, within each impact category were undertaken by the WAR algorithm to ensure that values of different pollution categories contain the same units to allow for their combination [40]. The normalisation of the impact scores also ensures that values from different categories will have on the average equivalent scores thus eliminating unintentional bias in the calculation of the PEI indexes [40]. The normalisation of the impact scores of the potential impact, due to component $k$ is achieved by the WAR algorithm using the following normalisation scheme [40],

$$
\phi_{k l}^{s}=\frac{(\text { Score })_{k l}}{\left[(\text { Score })_{k}\right]_{l}}
$$

where (Score $)_{k l}$ represents the impact score or value of chemical $k$ on some arbitrary scale for impact category $l$ and $\left[(\text { Score })_{k}\right]_{l}$ represents the average impact score or value of all chemicals in category $l$.

In the present study only the energy inputs (heating utilities) required for the ISHSE and the DST biodiesel production processes were assumed to be provided by natural gas as a fossil-based, non-renewable energy source. The WAR software is freely available on the EPA website. Using information on participating chemical components, inlet, product and waste streams, and total energy consumption, the PEI per kg of products of both processes have been determined.

Table 2. Impact categories in the WAR algorithm (adapted from Gangadharan et al. [48]).

\begin{tabular}{ccc}
\hline General Impact Category & Impact Category & Measure of Impact Category \\
\hline \multirow{2}{*}{ Human toxicity } & Ingestion (HTPI) & LD50 \\
& Inhalation/dermal (HTPE) & OSHA PEL \\
\hline \multirow{2}{*}{ Ecological toxicity } & Aquatic toxicity (ATP) & Fathead Minnow LC50 \\
& Terrestrial toxicity (TTP) & LD50 \\
\hline \multirow{2}{*}{ Global atmospheric impacts } & Global warming potential (GWP) & ODP \\
\hline \multirow{2}{*}{ Regional atmospheric impacts } & Ozone depletion potential (ODP) & AP \\
& Photochemical oxidation potential (PCOP) & PCOP \\
\hline
\end{tabular}

\section{Results}

The ASPEN plus models for the DST and the alternative ISHSE catalyst-free biodiesel production pathways were designed and shown in Figures 6 and 7, respectively. In Figure 6, the inlet feed streams of TAG and METHANOL, are initially mixed (MIXER-1) such that the required methanol to oil feed ratio of $42: 1$ is maintained and the mixture is subsequently pressurised to $28 \mathrm{MPa}$ (pump $\mathrm{P}-1)$. The pressurised mixed stream (1-P) is subsequently fed to the continuously stirred tank (CSTR) reactors (ST-1, ST-2, ST-3 and ST-4), arranged in series to improve the conversion of TAG to FAME. Each CSTR reactor utilised in the supercritical TAG transesterification reaction is maintained at a temperature and a pressure of $280^{\circ} \mathrm{C}$ and $28 \mathrm{MPa}$ respectively. Stream (5) produced after the 
supercritical transesterification is then cooled using the heat exchanger (H-1) to $25^{\circ} \mathrm{C}$ and depressurised to $1 \mathrm{~atm}$ using a valve (V-1). The recovery of excess methanol from the FAMEs, unreacted TAGs and glycerol present in stream (6) is initially undertaken via vaporisation of the excess methanol in a vaporiser (VAP) at a temperature of $90{ }^{\circ} \mathrm{C}$ and pressure of $1 \mathrm{~atm}$. The recovered hot methanol represented by stream (7) is then cooled to a temperature of $25^{\circ} \mathrm{C}$ using a heat exchanger (H-2) and with the recovered methanol at a temperature of $25^{\circ} \mathrm{C}$ and under atmospheric pressure, represented by the METH-RCV stream. After the vaporisation of excess methanol, the residual mixture, represented by stream (8), is subjected to the distillation process using a distillation column (DISTL-1, 10 stages and reflux ratio 1.5) to facilitate the recovery of the FAME (BIODIESL) produced at the reboiler. The FAME containing stream (12) is cooled to $25^{\circ} \mathrm{C}$ using a heat exchanger (H-5). In the simulated DST process, the biodiesel (BIODIESL) stream is characterised by a FAME content (99 wt. \%), that satisfies the European EN 14214 standard for the minimum required methyl ester content for biodiesel and is specified by a mass fraction of FAME of $\geq 96.5 \%$ per unit mass of the biodiesel product [49]. Additional processing steps are introduced to enable the recovery of any remaining methanol present in the exit streams from the condenser of the distillation column (DISTL-1) to further avoid wastage of useful masses of methanol. Recovery of additional masses of methanol is achieved via a second distillation process, using another distillation column (DISTL-2, 6 stages and reflux ratio 1). Finally, the recovered methanol (ME-RCV-2) and glycerol (GLYCEROL) containing streams are cooled to $25^{\circ} \mathrm{C}$ using heat exchangers $\mathrm{H}-3$ and $\mathrm{H}-4$ respectively. Glycerol containing stream is considered as a waste stream due to the low price of purified glycerol as discussed in later sections. 


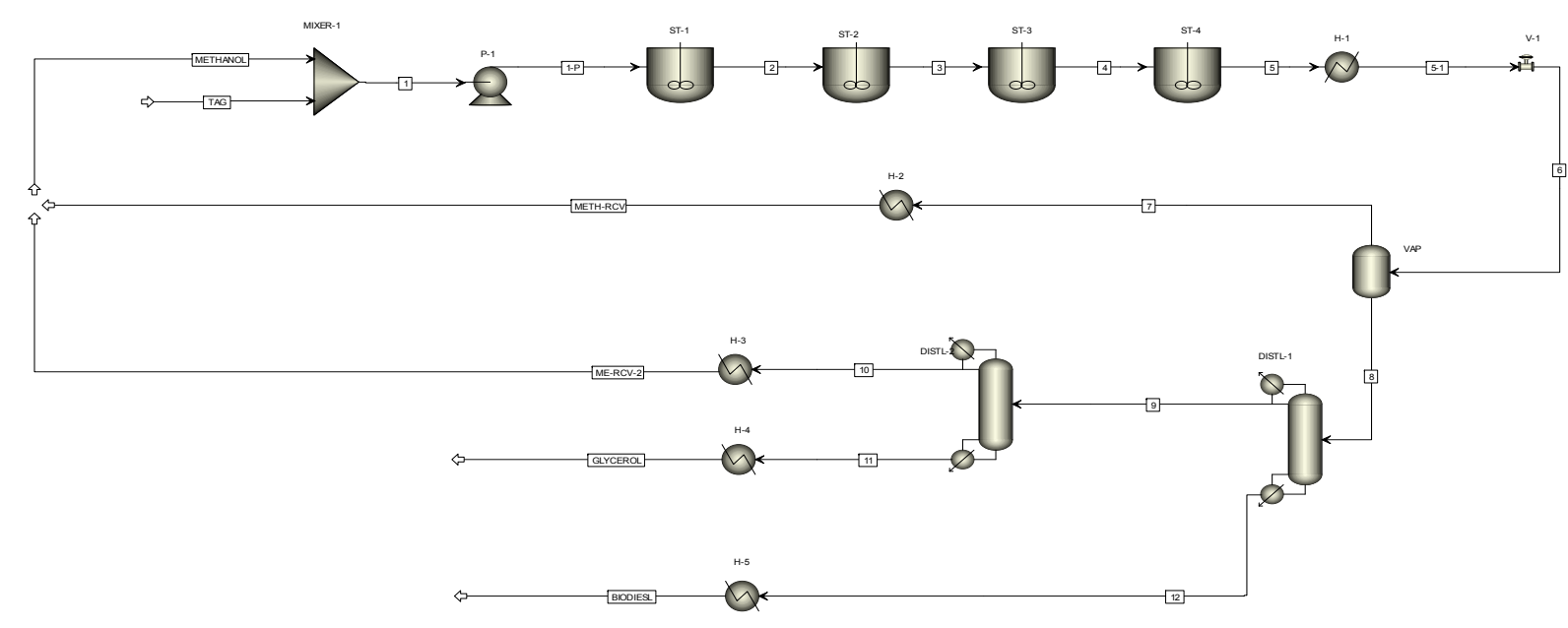

Figure 6. The process flow sheet for the simulated direct supercritical transesterification (DST) process.

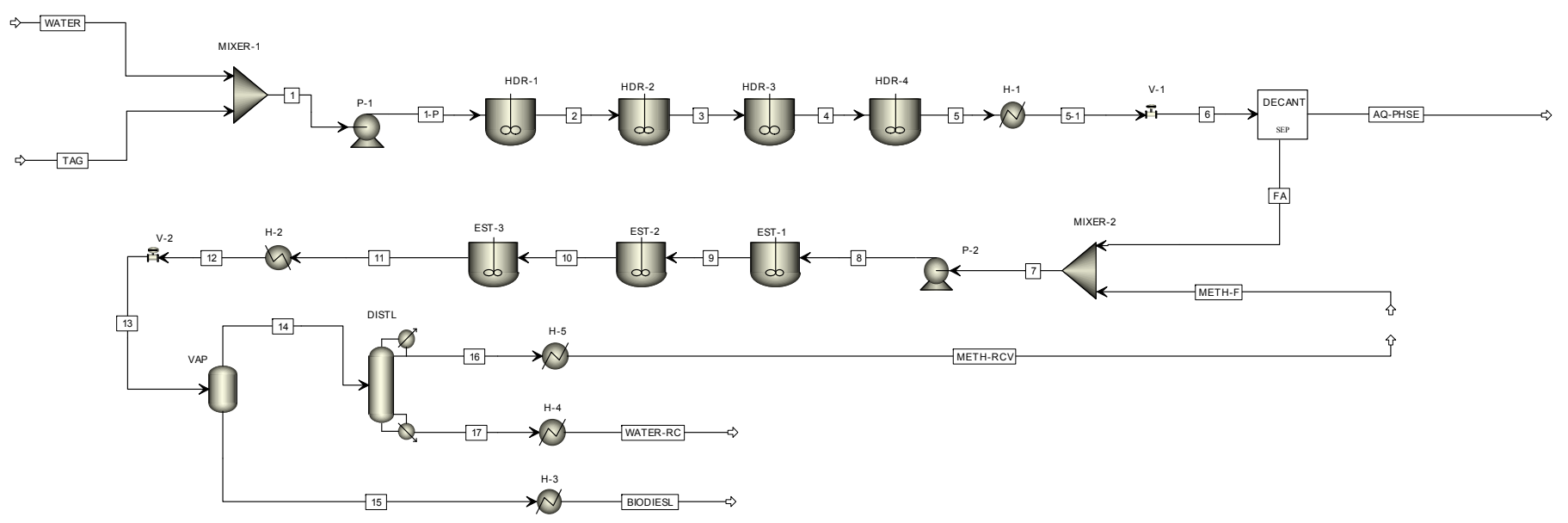

Figure 7. The process flow sheet for the simulated integrated subcritical lipid hydrolysis and supercritical esterification (ISHSE) process. 
In Figure 7, the inlet feed streams of TAG and water, are initially mixed (MIXER-1) and then pressurised to $7 \mathrm{MPa}$ using a pump (P-1). The pressurised mixed stream (1-P) is subsequently fed to continuously stirred tank (CSTR) reactors (HDR-1, HDR-2, HDR-3 and HDR-4), arranged in series to improve the conversion of the TAG to FAs. Each CSTR reactor utilised in modelling the subcritical TAG hydrolysis reaction is maintained at a temperature and pressure of $270{ }^{\circ} \mathrm{C}$ and $7 \mathrm{MPa}$ respectively. Stream (5) produced after subcritical lipid hydrolysis is then cooled using a heat exchanger (H-1) to $25^{\circ} \mathrm{C}$ and is depressurised to $1 \mathrm{~atm}$ using a valve (V-1). Separation of the FAs was achieved via simple decantation since the phases present (non-polar fatty acid and polar water) are essentially immiscible at mild temperatures [50]. The separated FAs in the OIL-PHSE stream are subsequently mixed with methanol such that the desired methanol to FA molar feed ratio of 20:1 is maintained. The properly mixed inlet feed stream (7), composed of FA and methanol is then pressurised to $8.1 \mathrm{MPa}$ using a pump (P-2) and is subsequently fed to multiple CSTR reactors (EST-1, EST-2 and EST-3), arranged in series to improve the percentage conversion of the FAs to FAMEs. Each CSTR reactor utilised in modelling the supercritical FA esterification reaction is maintained at a temperature and a pressure of $250^{\circ} \mathrm{C}$ and 8.1 MPa respectively. The product stream (11) mainly composed of unreacted methanol, water and FAMEs is cooled to $25^{\circ} \mathrm{C}$ using a heat exchanger (H-2) and is depressurised to $1 \mathrm{~atm}$ using a valve (V-2). The cooled and depressurised product stream (13) is then subjected to vapourisation (VAP) at a temperature of $140{ }^{\circ} \mathrm{C}$ and a pressure of $1 \mathrm{~atm}$ respectively to vaporise any methanol and water impurities that may be present in the biodiesel (BIODIESL) product. This biodiesel product is cooled to $25{ }^{\circ} \mathrm{C}$ using heat exchanger (H-3). The vapour (stream 14) composed mainly of methanol and water is processed for methanol recovery via the distillation process using the distillation column (DISTL, 10 stages and reflux ratio 10). This stage is considered necessary to enable methanol recovery for reuse. The higher boiling temperature stream 17 (WATER-RC) and the lower boiling temperature methanol (stream 16) are also cooled to $25^{\circ} \mathrm{C}$ using heat exchangers $\mathrm{H}-4$ and $\mathrm{H}-5$ respectively. Stream 17 and methanol stream are cooled to facilitate easy handling for secondary uses and future esterification reactions respectively. The water containing streams represented by AQ-PHSE and WATER-RC in Figure 7 are considered as waste streams. In the simulated ISHSE process the biodiesel (BIODIESL) stream is characterised by a FAME content ( $97 \mathrm{wt}$. \%), that satisfies the European EN 14214 standard for the minimum required methyl ester content for biodiesel and is specified as $\geq 96.5 \%$ per unit mass of the biodiesel product [49].

Tables 3 and 4 present the mass balance results of major streams in the DST and the ISHSE biodiesel production processes respectively. For both processes, $849.9 \mathrm{~kg}$ of biodiesel/ $\mathrm{h}$ is produced with methyl ester contents greater than $96.5 \mathrm{wt}$. \% in the respective biodiesel products.

The thermal data is provided in Tables 5 and 6 were utilised in formulating the composite curves (CC) and grand composite curve (GCC) for both ISHSE and DST biodiesel production processes.

After undertaking heat integration via the pinch methodology as stated earlier in Section 2, the CC and GCC for the DST process and the CC and GCC for the ISHSE process have been presented in Figures 8-11 respectively. The generated HEN for the DST and ISHSE process and a chart showing the comparative view of the utility requirement before and after heat integration for both processes have also been presented in Figures 12-14 respectively.

To assess the performance of the alternative high pressure biodiesel production processes and also identify the major contributors to the environmental outcomes, a comparative assessment of the output potential environmental impacts (PEI) per $\mathrm{kg}$ of products for both processes were investigated. The potential environmental impact (PEI) per $\mathrm{kg}$ of products due to the DST and the ISHSE biodiesel production processes is presented in Figure 15. Figure 15 shows that the ISHSE biodiesel production process has a PEI of about 1.05 times greater than the PEI of the DST process. 
Table 3. The simulation results of the major streams in the process flow sheet for the DST process.

\begin{tabular}{|c|c|c|c|c|c|c|c|c|c|c|}
\hline Stream Name & 1 & 2 & 5 & 9 & BIODIESL & GLYCEROL & ME-RCV-2 & METH-RCV & METHANOL & TAG \\
\hline Temperature $\left({ }^{\circ} \mathrm{C}\right)$ & 25 & 280 & 280 & 72 & 25 & 25 & 25 & 25 & 25 & 25 \\
\hline Pressure (MPa) & 0.1013 & 28 & 28 & 0.1013 & 0.1013 & 0.1013 & 0.1013 & 0.1013 & 0.1013 & 0.1013 \\
\hline \multicolumn{11}{|l|}{ Mass fraction } \\
\hline Methanol & 0.603 & 0.572 & 0.560 & 0.401 & Trace & 0.221 & 1 & 1 & 1 & 0 \\
\hline Triglyceride & 0.397 & 0.109 & 0.002 & Trace & 0.006 & Trace & Trace & Trace & 0 & 1 \\
\hline FAME & 0 & 0.289 & 0.396 & 0.139 & 0.994 & 0.181 & Trace & Trace & 0 & 0 \\
\hline Glycerol & 0 & 0.03 & 0.041 & 0.460 & Trace & 0.598 & Trace & Trace & 0 & 0 \\
\hline Mass Flows (kg/h) & 2198.9 & 2198.9 & 2198.9 & 194.8 & 849.9 & 149.9 & 44.9 & 1154.2 & 1326.2 & 872.7 \\
\hline
\end{tabular}

Table 4. The simulation results of the major streams in the process flow sheet for the ISHSE process.

\begin{tabular}{|c|c|c|c|c|c|c|c|c|c|c|c|c|c|}
\hline Stream Name & 1 & 2 & 5 & 7 & 9 & AQ-PHSE & BIODIESL & FA & METH-F & METH-RCV & TAG & WATER & WATER-RC \\
\hline Temperature $\left({ }^{\circ} \mathrm{C}\right)$ & 25 & 270 & 270 & 25 & 250 & 27 & 25 & 27 & 25 & 25 & 25 & 25 & 25 \\
\hline Pressure $(\mathrm{MPa})$ & 0.1013 & 7 & 7 & 0.1013 & 8.1 & 0.1013 & 0.1013 & 0.1013 & 0.1013 & 0.1013 & 0.1013 & 0.1013 & 0.1013 \\
\hline \multicolumn{14}{|l|}{ Mass Fractions } \\
\hline Oleic acid & 0 & 0.336 & 0.455 & 0.305 & 0.074 & Trace & 0.013 & 0.995 & 0 & Trace & 0 & 0 & 0.002 \\
\hline Methanol & 0 & 0 & 0 & 0.693 & 0.667 & 0 & 0.012 & 0 & 1 & 0.979 & 0 & 0 & Trace \\
\hline Triglyceride & 0.477 & 0.126 & 0.002 & 0.002 & 0.002 & Trace & 0.004 & 0.005 & 0 & Trace & 1 & 0 & 0.026 \\
\hline Water & 0.523 & 0.501 & 0.494 & 0 & 0.015 & 0.909 & 0.001 & 0 & 0 & 0.021 & 0 & 0 & 0.595 \\
\hline FAME & 0 & 0 & 0 & 0 & 0.243 & 0 & 0.97 & 0 & 0 & Trace & 0 & 1 & 0.378 \\
\hline Glycerol & 0 & 0 & 0 & 0 & 0 & 0.091 & 0 & 0 & 0 & 0 & 0 & 0 & 0 \\
\hline Mass Flows & 1768.7 & 1768.7 & 1768.7 & 2634.9 & 2634.9 & 960.7 & 849.9 & 808.1 & 1826.9 & 1764.9 & 844.2 & 924.5 & 20.1 \\
\hline
\end{tabular}


Table 5. Hot and cold streams extracted from Simulation flowsheet for the ISHSE biodiesel production process.

\begin{tabular}{cccc}
\hline \multirow{2}{*}{ Stream Description } & \multicolumn{2}{c}{ Temperature $\left({ }^{\circ} \mathbf{C}\right)$} & Duty $(\mathbf{k W})$ \\
\cline { 2 - 4 } & Inlet & Outlet & - \\
\hline & Hot streams & \\
\hline 5_To_5-1 & 270 & 25 & 430.42 \\
11_To_12 & 250 & 25 & 710.50 \\
15_To_BIODIESL & 140 & 25 & 55.75 \\
16_To_METH-RCV & 65.1 & 25 & 67.00 \\
HDR-2_heat & 270 & 269.5 & 13.97 \\
HDR-3_heat & 270 & 269.5 & 3.70 \\
HDR-4_heat & 270 & 269.5 & 0.98 \\
To Condenser at DISTL_To_16 & 66 & 65.1 & 6058.96 \\
17_To_WATER-RC & 101.1 & 25 & 1.37 \\
\hline & Cold streams & \\
\hline EST-1_heat & 35.1 & 250 & 718.5 \\
EST-2_heat & 250 & 250.5 & 5.62 \\
EST-3_heat & 250 & 250.5 & 1.36 \\
VAP_heat & 27.3 & 140 & 736.00 \\
HDR-1_heat & 35.3 & 270 & 366.40 \\
To Reboiler at DISTL_To_17 & 100 & 101.1 & 5771.50 \\
\hline
\end{tabular}

Table 6. Hot and cold streams extracted from Simulation flowsheet for the DST biodiesel production process.

\begin{tabular}{cccc}
\hline \multirow{2}{*}{ Stream Description } & \multicolumn{2}{c}{ Temperature $\left({ }^{\circ} \mathbf{C}\right)$} & Duty $(\mathbf{k W})$ \\
\cline { 2 - 4 } & Inlet & Outlet & - \\
\hline & Hot streams & \\
\hline 5_To_5-1 & 280 & 25 & 588.57 \\
7_To_METH-RCV & 90 & 25 & 406.0 \\
10_To_ME-RCV-2 & 64.5 & 25 & 1.63 \\
11_To_GLYCEROL & 79 & 25 & 5.46 \\
12_To_BIODIESL & 344.1 & 25 & 184.90 \\
ST-2_heat & 280 & 279.5 & 9.25 \\
ST-3_heat & 280 & 279.5 & 2.55 \\
ST-4_heat & 280 & 279.5 & 0.70 \\
To Condenser at DISTL-1_To_9 & 254.3 & 71.8 & 164.60 \\
To Condenser at DISTL-2_To_10 & 69.6 & 64.5 & 27.50 \\
\hline & Cold streams & & \\
\hline ST-1_heat & 69.4 & 280 & 483.50 \\
VAP_heat & 27.2 & 90 & 441.03 \\
\hline To Reboiler at DISTL-1_To_12 & 343.5 & 344.1 & 317.54 \\
To Reboiler at DISTL-2_To_11 & 69.7 & 79.0 & 27.90 \\
\hline
\end{tabular}

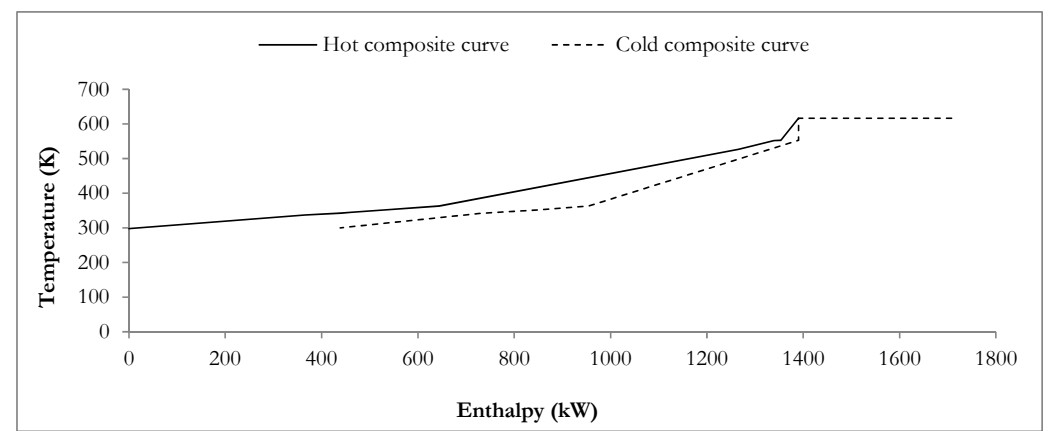

Figure 8. Composite curves (CC) for minimum driving temperature of $10 \mathrm{~K}$ for DST. 


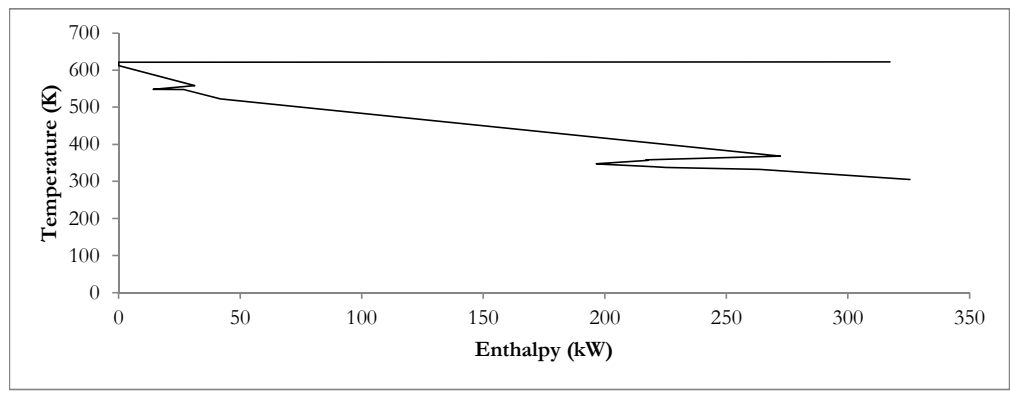

Figure 9. Grand composite curve (GCC) for minimum driving temperature of $10 \mathrm{~K}$ for DST.

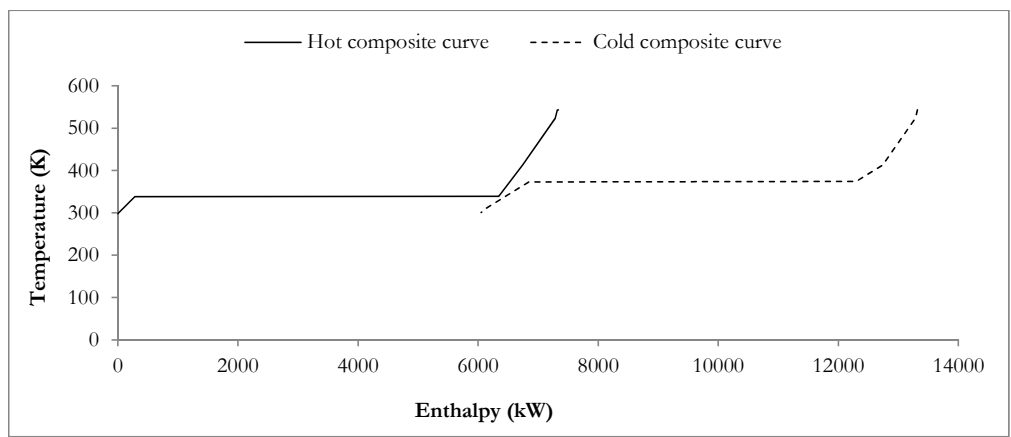

Figure 10. Composite curves (CC) for minimum driving temperature of $10 \mathrm{~K}$ for ISHSE.

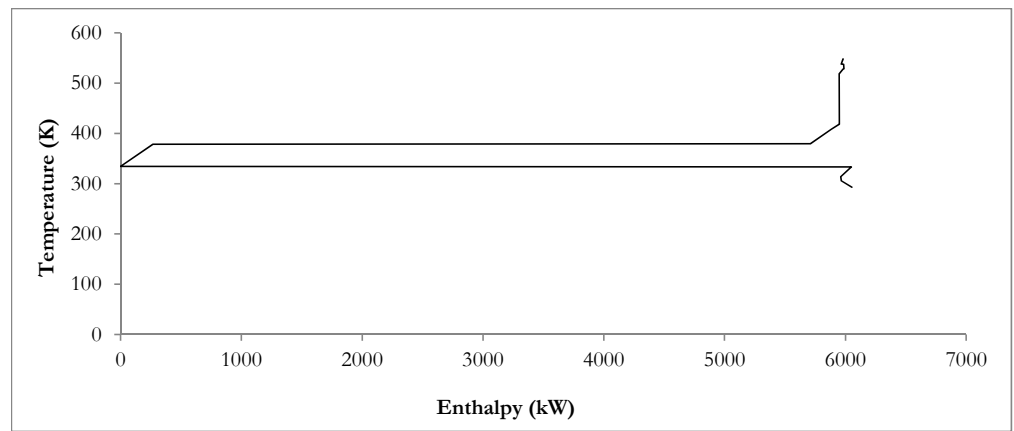

Figure 11. Grand composite curve (GCC) for minimum driving temperature of $10 \mathrm{~K}$ for ISHSE.

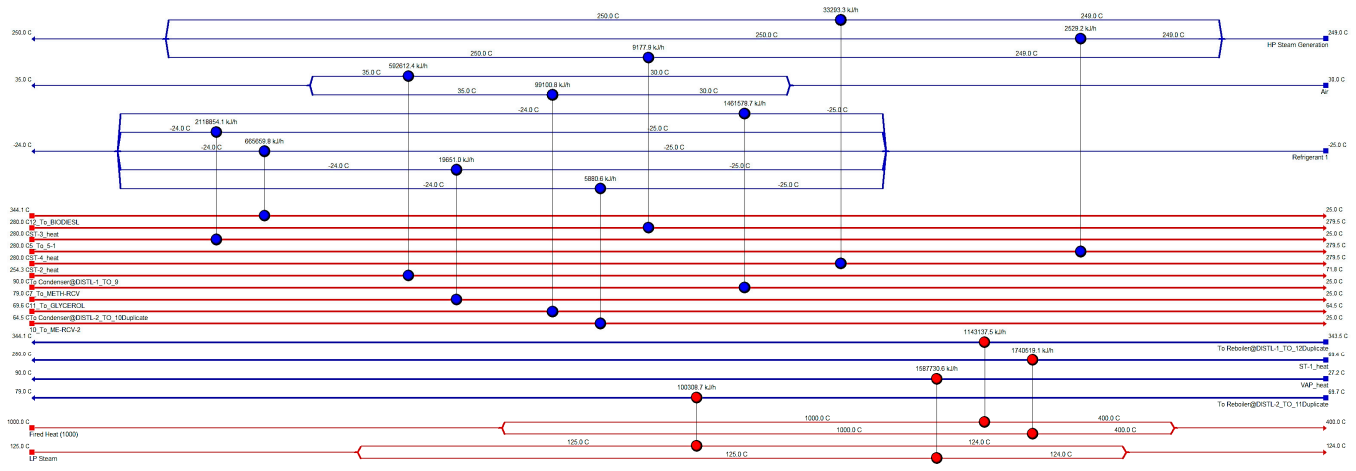

Figure 12. Aspen Energy analyser HEN output for the DST process (blue and red colours representing the cold streams and hot streams respectively). 


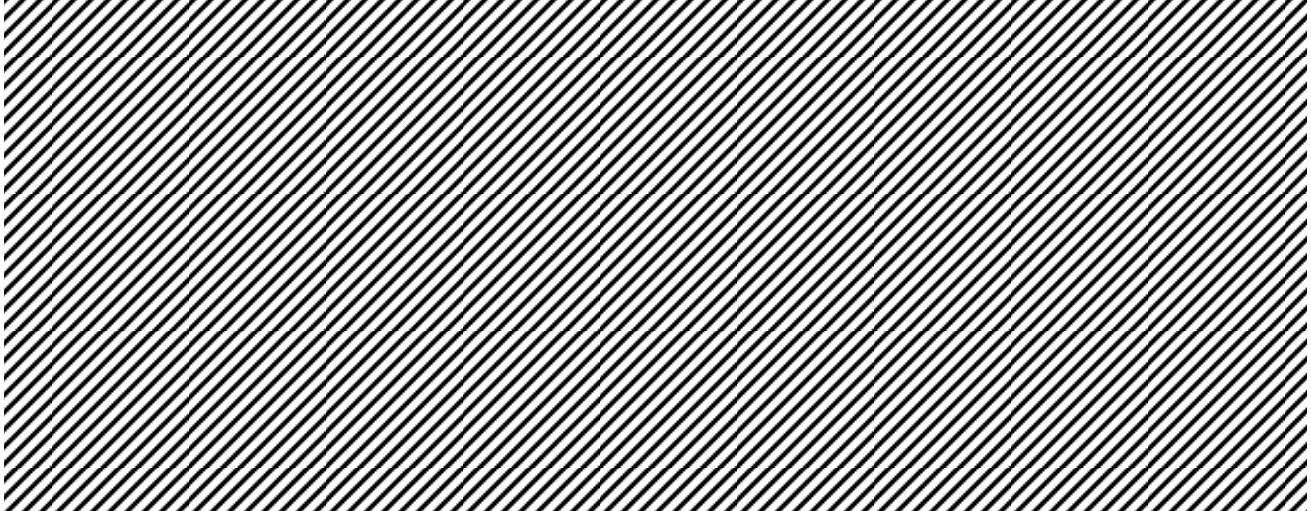

Figure 13. Aspen Energy analyser HEN output for the ISHSE process (blue and red colours representing the cold streams and hot streams respectively).

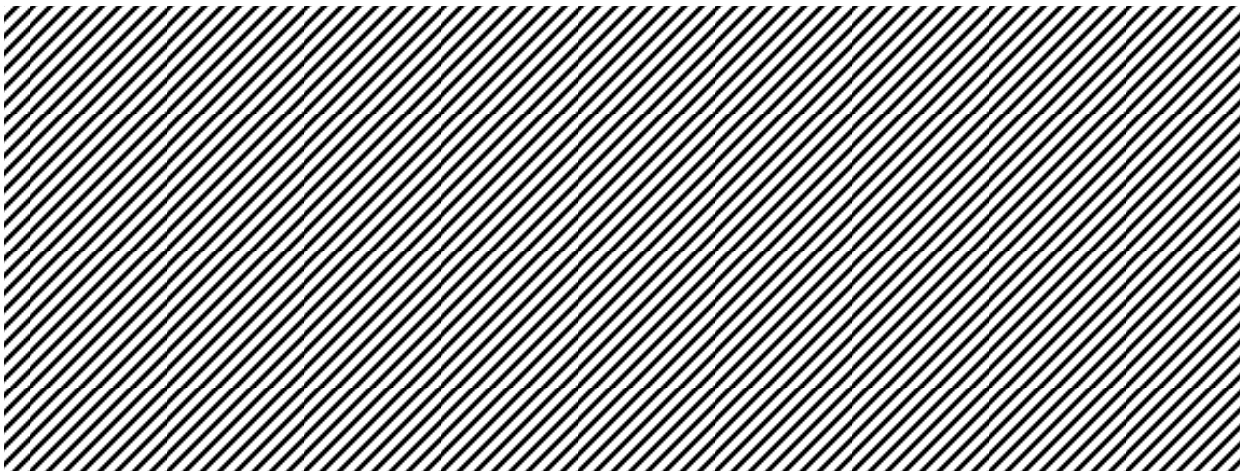

Figure 14. Utility requirement of DST and ISHSE processes.

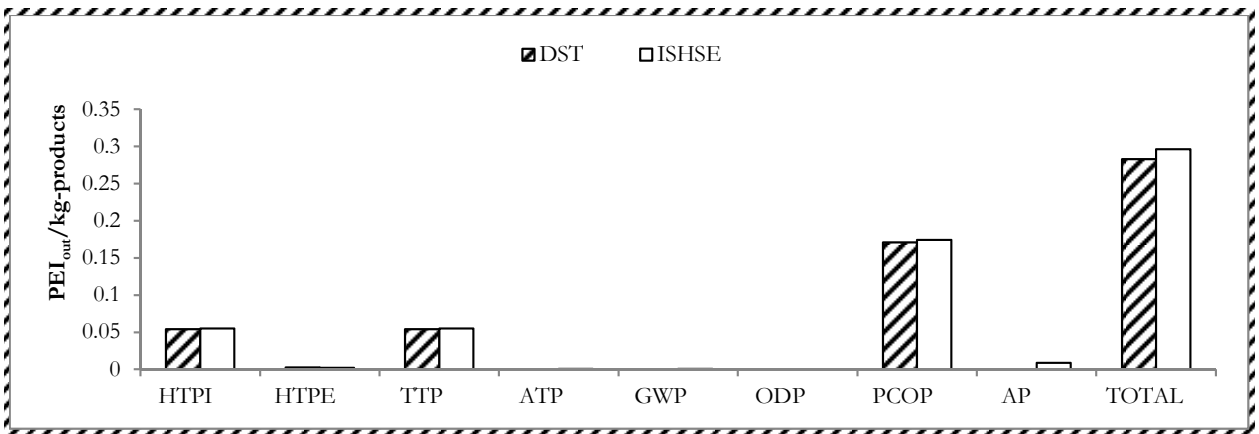

Figure 15. The comparative assessment of the potential environmental impacts of the ISHSE and the DST biodiesel production processes.

\section{Discussion}

From the mass balance results for the DST and the ISHSE processes presented in Tables 3 and 4 respectively, it is seen that methanol recovery is highly efficient with a methanol percentage recovery of $90 \%$ and $97 \%$ calculated for the DST process and ISHSE process respectively. This observation implies that methanol consumption in the ISHSE and DST processes are $54.8 \mathrm{~kg} / \mathrm{h}$ and 132.62 respectively. This observation is expected due to the reduced methanol to FA mole ratio required during esterification reaction relative to the high methanol to TAG mole ratio required during transesterification reactions as discussed in the introductory section of this paper. The DST biodiesel production process is characterised by one major 'waste' (GLYCEROL) stream which is generated at a mass flow rate of $149.9 \mathrm{~kg} / \mathrm{h}$. This observation contrasts with the ISHSE biodiesel production process which is 
characterised by two major 'waste' streams namely, the WATER-RC and AQ-PHSE streams with a combined flow rate $980.8 \mathrm{~kg} / \mathrm{h}$. This initial observation suggests that the ISHSE biodiesel production process may present a greater waste management challenge than the DST process. Furthermore, the recovery of pure glycerol from the GLYCEROL stream and the AQ-PHSE stream of the DST and the ISHSE biodiesel processes respectively is not considered in this study since the purification of the glycerol makes no economic sense. This is because the cost of pure glycerol is very low due to current glut of glycerol supply arising from increased global biodiesel production capacities [51]. It therefore implies that there is a clear economic disadvantage of introducing additional glycerol purification steps in both processes.

A consideration of the energy balance data presented in Tables 5 and 6 shows that prior to heat integration energy duties of $14,940 \mathrm{~kW}$ and the $2661 \mathrm{~kW}$ are required by the ISHSE and the DST processes respectively. In both processes the distillation columns and the reactors constitute major contributors to the calculated energy duties. Clearly exploration of opportunities for heat recovery will serve to improve the energetics of both processes. Heat recovery was therefore undertaken via pinch analysis as discussed in Section 2 above. Comparing Figures 8 and 10, it can the observed that the ISHSE provides reduced opportunities for heat recovery relative to the heat recovery opportunities available for in the DST process implying the significant duty required during the ISHSE process relative to the DST process will be retained. The Aspen Energy Analyser ${ }^{\circledR}$ determined that the minimum heating utility $\left(\mathrm{Q}(\mathrm{H})_{\mathrm{min}}\right)$ and the minimum cooling utility $\left(\mathrm{Q}(\mathrm{C})_{\min }\right)$ for the DST process are $317.5 \mathrm{~kW}$ and $438.8 \mathrm{~kW}$ respectively while the $\mathrm{Q}(\mathrm{H})_{\min }$ and $\mathrm{Q}(\mathrm{C})_{\min }$ for the ISHSE process are $6269 \mathrm{~kW}$ and $6012 \mathrm{~kW}$ respectively. Figures 9 and 11, highlight the plot of the heat load difference between hot and cold composite curves, for the DST and ISHSE process respectively, as a function of temperature such that the pinch point, which is the point where there is no heat flow, is identified by the point the curve touches the Temperature (y) axis. The Aspen Energy analyser has also determined that the pinch temperature is $66{ }^{\circ} \mathrm{C}$ for the ISHSE biodiesel production process and $344{ }^{\circ} \mathrm{C}$ for the DST biodiesel production process. Figures 12 and 13 depict the stream information and the Aspen Energy analyser generated HEN grid diagram for the DST and the ISHSE process flowsheets respectively. These HEN grid diagrams highlight the energy duties satisfied using necessary external cooling utilities and heating utilities and the required number of heat exchangers. For the DST process shown in Figure 12, 14 heat exchangers and 5 utilities were utilised. Figure 12 also shows that the heating requirements were satisfied using low pressure steam (LP stream) and fired heat (1000) while the cooling requirements were satisfied using a refrigerant (refrigerant 1), air and via high pressure steam generation (HP steam generation). It can also be seen that most of the cooling requirements of the DST process can be satisfied with the use of a refrigerant with a bulk of the heating requirements satisfied using the fired heater. Similarly in the ISHSE process 14 heat exchangers were utilised. More utilities (7) compared to the DST process were however required to satisfy the energy requirements, as expected, due to the calculated higher heating and cooling requirements. Figure 13 shows that the cooling requirements were provided using a refrigerant (refrigerant 1), air and a high pressure steam generation (HP steam generation) plant. The heating requirements were satisfied using low pressure steam (LP steam), fired heat (Fired heat (1000)), moderate pressure steam (MP steam) and hot oil (Hot oil). Most of the cooling requirements were satisfied using air via heat transfer from the condenser of the distillation column with most of the heating requirements satisfied using LP steam to providing the heat required by the reboiler of the distillation column. It is crucial to note at this juncture that the HEN diagrams (as shown in Figures 12 and 13) constitute only one of the possible designs that can be utilised in reducing the heating and the cooling duties, given that, multiple designs are also possible for the given process for different $\Delta \mathrm{T}_{\text {min }}$ values. Further studies with respect to cost minimisation for optimal heat integration may also be undertaken in the future. Figure 14 therefore illustrates the difference in the energy duties of both processes before heat integration and after heat integration. It can be seen clearly that while an energy saving of $71.6 \%$ are possible using the DST biodiesel production process, energy savings of only $17.8 \%$ is possible in the ISHSE biodiesel production process. 
Figure 15 shows that the indexes photochemical oxidation potential (PCOP) index and acidification potential (AP) index constitute the major impact categories of the PEI for the ISHSE and the DST biodiesel production processes. Figure 15 also shows that the highest contributor to the PEI for the ISHSE and the DST processes is the PCOP index impact category. This may be explained by acknowledging that masses of volatile methanol were utilised in both biodiesel production processes. This is because volatiles are capable of producing photochemical smog via photochemical reactions with precursor pollutants, such as nitrous oxides $\left(\mathrm{NO}_{\mathrm{x}}\right)$ generated during fossil fuel utilisation [52]. The higher the mass of methanol utilized, the higher the risk of smog formation, thus explaining the observed higher contribution of the PCOP index impact category in the ISHSE (methanol used, $1826.9 \mathrm{~kg} / \mathrm{h}$ ) process relative to the DST (methanol used, $1326.2 \mathrm{~kg} / \mathrm{h}$ ) process. Furthermore, both processes will present almost similar pollution risks to humans and land as illustrated by the human toxicity potential by ingestion (HTPI) and terrestrial toxicity potential (TTP) indexes. The almost similar indexes (HTPI, TTP) for ISHSE $(0.0549,0.0549)$ and DST $(0.0542,0.0542)$ suggests that although a reduced mass of methanol solvent was utilised during the ISHSE process, higher masses of the combined waste streams will result in an almost similar impact to the impact of the higher methanol demanding DST process, on humans (HTPI) and land (TTP). The utilization of fossil fuels will result in the release of $\mathrm{CO}_{2}, \mathrm{NO}_{x}$ and $\mathrm{SO}_{2}$ which when combined with atmospheric moisture, will lead to the formation of weak acids such as carbonic acid $\left(\mathrm{H}_{2} \mathrm{CO}_{3}\right)$ and sulfurous acid $\left(\mathrm{H}_{2} \mathrm{SO}_{3}\right)$ which constitute the major causes of acid rain [53]. Thus higher fossil energy consumption as in the case of the ISHSE process relative to the DST process will result in a higher acidification potential as illustrated by the higher AP index of the ISHSE process relative to the AP index of the DST process. The present study therefore suggests that the DST biodiesel process may therefore be conclusively considered as a (slightly) more environmentally favourable catalyst-free biodiesel production process. To improve the PEI of the ISHSE biodiesel production process relative to the DST biodiesel production, some consideration must be given to reducing the large quantities of primary fuel via the use of cheap energy sources. This is because the utilisation of alternative energy sources such as solar power for lower energy process, e.g., vapourisation of the methanol, will reduce the volumes of gases such as $\mathrm{SO}_{2}, \mathrm{CO}_{2}$ and $\mathrm{NO}_{\mathrm{x}}$ that characterise fossil fuel use, thus reducing the output rate of PEI due to fuel utilisation. The utilisation of the large mass of the waste streams from both the ISHSE and DST processes as a useful feedstock for secondary value addition via anaerobic digestion for cheap bioenergy generation may also be explored. Furthermore, the utilisation of 'filters' to clean gaseous emissions during the utilisation of fossil-based fuels could also be considered.

\section{Conclusions}

This analysis established that the integrated subcritical lipid hydrolysis and supercritical esterification (ISHSE) and direct supercritical transesterification (DST) biodiesel production processes are characterised by very different rates of energy consumption after heat integration. The minimum cooling $(317.5 \mathrm{~kW})$ and heating utility $(438.8 \mathrm{~kW})$ of the DST process was shown to be about $95 \%$ and about $93 \%$ less than the minimum heating $(6012 \mathrm{~kW})$ and cooling utility $(6269 \mathrm{~kW})$ of the ISHSE process respectively. Further investigations to ascertain the actual environmental performances of both processes were also undertaken using the waste reduction algorithm.

Combining the waste reduction algorithm and energetic assessments, this paper therefore demonstrated that the DST biodiesel production process constituted a more favourable catalyst-free biodiesel production process, overall. The importance of heat integration via the utilisation of hot stream as a heat source for cold streams was also emphasised as a pathway for improving the environmental performances of both process. This is because such heat integration will facilitate reduction in energy demand and reduction in the fossil fuel demand in the ISHSE and DST biodiesel production processes and thus reduces the volumes of $\mathrm{SO}_{2}, \mathrm{CO}_{2}$ and $\mathrm{NO}_{\mathrm{x}}$ that characterise fossil fuel use, thus reducing the contribution of the index of the acidification potential and the index of global warming potential impact categories to the potential environmental impacts. Although 
possible improvements in the catalyst-free biodiesel production designs are recognised, the feasibility of introducing the suggested design modifications will be dependent on the engineering economics and process efficiency concerns thus indicating the need for further investigations with respect to the economic performances and optimisation of the both processes.

Acknowledgments: Oseweuba Valentine Okoro gratefully acknowledges the financial support of the University of Otago via the Otago Doctoral scholarship.

Author Contributions: All authors contributed extensively to the work presented in this paper. Oseweuba Valentine Okoro conceived the simulation study and drafted the manuscript; Zhifa Sun and John Birch revised the paper.

Conflicts of Interest: The authors declare no conflict of interest.

\section{References}

1. Okoro, O.; Sun, Z.; Birch, J. Meat processing dissolved air flotation sludge as a potential biodiesel feedstock in New Zealand: A predictive analysis of the biodiesel product properties. J. Clean. Prod. 2017, 168, 1436-1447. [CrossRef]

2. Saka, S.; Kusduiana, D.; Minami, E. Non-catalytic biodiesel fuel production with supercritical methanol technologies. J. Sci. Ind. Res. 2006, 65, 420-425.

3. Glisic, S.; Skala, D. The problems in design and detailed analyses of energy consumption for biodiesel synthesis at supercritical conditions. J. Supercrit. Fluids 2009, 49, 293-301. [CrossRef]

4. Mondala, A.; Liang, K.; Toghiani, H.; Hernandez, R.; French, T. Biodiesel production by in situ transesterification of municipal primary and secondary sludges. Bioresour. Technol. 2009, 100, 1203-1210. [CrossRef] [PubMed]

5. Okoro, O.; Sun, Z.; Birch, J. Enhanced fatty acid generation from meat processing dissolved air flotation sludge. In Proceedings of the 25th European Biomass Conference and Exhibition, Stockholm, Sweden, 12-15 June 2017.

6. Jin, T.; Wang, B.; Zeng, J.; Yang, C.; Wang, Y.; Fang, T. Esterification of free fatty acids with supercritical methanol for biodiesel production and related kinetic study. RSC Adv. 2015, 5, 52072-52078. [CrossRef]

7. Sawangkeaw, R.; Bunyakiat, K.; Ngamprasertsith, S. Effect of co-solvents on production of biodiesel via transesterification in supercritical methanol. Green Chem. 2007, 9, 679-685. [CrossRef]

8. Abdulagatov, I.; Polikhronidi, N.; Abdurashidova, A.; Kiselev, S.B.; Ely, J.F. Thermodynamic Properties of Methanol in the Critical and Supercritical Regions. Int. J. Thermophys. 2005, 26, 1327-1368. [CrossRef]

9. Lu, J.; Boughner, E.; Liotta, C.; Eckert, C. Nearcritical and supercritical ethanol as a benign solvent: Polarity and hydrogen-bonding. Fluid Phase Equilib. 2002, 198, 37-49. [CrossRef]

10. Hoffmann, M.; Conradi, M. Are There Hydrogen Bonds in Supercritical Methanol and Ethanol? J. Phys. Chem. B 1998, 102, 263-271. [CrossRef]

11. Patil, P.; Gude, V.; Mannarswamy, A.; Deng, S.; Cooke, P.; Munson-McGee, S.; Rhodes, I.; Lammers, P.; Nirmalakhandan, N. Optimization of direct conversion of wet algae to biodiesel under supercritical methanol conditions. Bioresour. Technol. 2011, 102, 118-122. [CrossRef] [PubMed]

12. Demirbas, A. Studies on cottonseed oil biodiesel prepared in non-catalytic SCF conditions. Bioresour. Technol. 2008, 99, 1125-1130. [CrossRef] [PubMed]

13. He, H.; Wang, T.; Zhu, S. Continuous production of biodiesel fuel from vegetable oil using supercritical methanol process. Fuel 2007, 86, 442-447. [CrossRef]

14. Tan, K.; Lee, K.; Mohamed, A. Optimization of supercritical dimethyl carbonate (SCDMC) technology for the production of biodiesel and value-added glycerol carbonate. Fuel 2010, 89, 3833-3839. [CrossRef]

15. Shin, H.; Lim, S.; Bae, S.; Oh, C. Thermal decomposition and stability of fatty acid methyl esters in supercritical methanol. J. Anal. Appl. Pyrolysis 2011, 92, 332-338. [CrossRef]

16. Silva, C.D.; Vladimir, O. Biodiesel production through non-catalytic supercritical transesterification: Current state and perspectives. Braz. J. Chem. Eng. 2014, 31, 271-285. [CrossRef]

17. Kusdiana, D.; Saka, S. Two-Step Preparation for Catalyst-Free Biodiesel Fuel Production Hydrolysis and Methyl Esterification. Appl. Biochem. Biotechnol. 2004, 115, 781-790. [CrossRef] 
18. Gutierrez Ortiz, F.J.; de Santa-Ana, P.; Segovia-Hernande, J.G.; Hernandez, S. Techno-economic assessment of an energy self-sufficient process to produce biodiesel under supercritical conditions. J. Supercrit. Fluids 2017, 129, 349-358. [CrossRef]

19. Gomez-Castro, F.I.; Rico-Ramirez, V.; Segovia-Hernandez, J.G.; Hernandez-Castro, S.; El-Halwagi, M.M. Simulation study on biodiesel production by reactive distillation with methanol at high pressure and temperature: Impact on costs and pollutant emissions. Comput. Chem. Eng. 2013, 52, 204-215. [CrossRef]

20. Martín, A.; Mato, F. Hint: An educational software for heat exchanger network design with the pinch method. Educ. Chem. Eng. 2008, 3, 6-14. [CrossRef]

21. Sadhukhan, J.; Ng, K.; Martinez-Hernandez, E. Heat integration and utility system design. In Biorefineries and Chemical Processes: Design, Integration and Sustainability Analysis, 1st ed.; Wiley: Chichester, UK, 2014; pp. 63-91.

22. Linnhoff, B.; Flower, J. Synthesis of heat exchanger networks: I. Systematic generation of energy optimal networks. AIChe J. 1978, 24, 633-642. [CrossRef]

23. Sinnot, R.; Towler, G. Chemical Engineering Design, 5th ed.; Elsevier: Burlington, VT, USA, 2009.

24. Gomez-Castro, F.I.; Rico-Ramirez, V.; Segovia-Hernandez, J.G.; Hernandez, S. Feasibility study of a thermally coupled reactive distillation process for biodiesel production. Chem. Eng. Process. Process Intensif. 2010, 49, 262-269. [CrossRef]

25. Minami, E.; Saka, S. Kinetics of hydrolysis and methyl esterification for biodiesel production in two-step supercritical methanol process. Fuel 2006, 85, 2479-2483. [CrossRef]

26. He, H.; Sun, S.; Wang, T.; Zhu, S. Transesterification kinetics of soybean oil for production of biodiesel in supercritical methanol. J. Am. Oil Chem. Soc. 2007, 84, 399-404. [CrossRef]

27. Freedman, B.; Bagby, M. Heats of combustion of fatty esters and triglycerides. J. Am. Oil Chem. Soc. 1989, 66, 1601-1605. [CrossRef]

28. Lapuerta, M.; Rodríguez-Fernández, J.; Armas, O. Correlation for the estimation of the density of fatty acid esters fuels and its implications. A proposed Biodiesel Cetane Index. Chem. Phys. Lipids 2010, 163, 720-727. [CrossRef] [PubMed]

29. Knothe, G. "Designer" Biodiesel: Optimizing Fatty Ester Composition to Improve Fuel Properties. Energy Fuels 2008, 22, 1358-1364. [CrossRef]

30. Teeter, H.; List, G. Methods of Preparation of Fatty Acids and Their Derivatives: Laboratory Exercises: AOCS Lipdi Library. Available online: http:/ / lipidlibrary.aocs.org/OilsFats/content.cfm?ItemNumber=41539 (accessed on 17 October 2017).

31. European Standard (EN). EN 14214: Automotive Fuels-Fatty Acid Methyl Esters (FAME) for Diesel Engines-Requirement Methods; European Committee for Standardization (CEN): Brussels, Belgium, 2009.

32. American Society for Testing and Materials (ASTM). D6751-08a Standard Specification for Biodiesel (B100) Fuel Blend Stock (B100) for Middle Distillate Fuels. ASTM Annual Book of Standards; American Society for Testing and Materials International: West Conshohocken, PA, USA, 2008.

33. Tang, Z.; Du, Z.; Min, E.; Gao, L.; Jiang, T.; Han, B. Phase equilibria of methanol-triolein system at elevated temperature and pressure. Fluid Phase Equilib. 2006, 239, 8-11. [CrossRef]

34. Apostolakou, A.; Kookos, I.; Marazioti, C.; Angelopoulos, K. Techno-economic analysis of a biodiesel production process from vegetable oils. Fuel Process. Technol. 2009, 90, 1023-1031. [CrossRef]

35. Perry, E.S.; Weber, W.H.; Daubert, B.F. Vapor Pressure of Phlegmatic Liquids I. Simple and Mixed Triglycerides. J. Am. Chem. Soc. 1949, 71, 3720-3726. [CrossRef]

36. Kocsisová, T.; Juhasz, J.; Cvengros, J. Hydrolysis of fatty acid esters in subcritical water. Eur. J. Lipid Sci. Technol. 2006, 108, 652-658. [CrossRef]

37. Sturzenegger, A.; Sturm, H. Hydrolysis of fats at high temperatures. Ind. Eng. Chem. 1951, 43, 510-515. [CrossRef]

38. Braun, M.; Altan, H.; Beck, S. Using regression analysis to predict the future energy consumption of a supermarket in the UK. Appl. Energy 2014, 130, 305-313. [CrossRef]

39. Quesada-Medina, J.; Olivares-Carrillo, P. Evidence of thermal decomposition of fatty acid methyl esters during the synthesis of biodiesel with supercritical methanol. J. Supercrit. Fluids 2011, 56, 56-63. [CrossRef]

40. Young, D.; Scharp, R.; Cabezas, H. The waste reduction (WAR) algorithm: Environmental impacts, energy consumption, and engineering economics. Waste Manag. 2000, 20, 605-615. [CrossRef] 
41. Rincón, L.; Jaramillo, J.; Cardona, C. Comparison of feedstocks and technologies for biodiesel production: An environmental and techno-economic evaluation. Renew. Energy 2014, 69, 479-487. [CrossRef]

42. Moncada, J.; Tamayo, J.; Cardona, C. Integrating first, second, and third generation biorefineries: Incorporating microalgae into the sugarcane biorefinery. Chem. Eng. Sci. 2014, 118, 126-140. [CrossRef]

43. Pistikopoulos, E.N.; Stefanis, S.K.; Livingston, A.G.A. Methodology for Minimum Environmental Impact Analysis. AICHe Symp. Ser. 1995, 35, 4128.

44. Shonnard, D.R.; Hiew, D.S. Comparative Environmental assessments of VOC Recovery and recycle design alaternatives for gaseous waste streams. Environ. Sci. Technol. 2000, 34, 5222-5228. [CrossRef]

45. Young, D.; Cabezas, H. Designing sustainable processes with simulation: The waste reduction (WAR) algorithm. Comput. Chem. Eng. 1999, 23, 1477-1491. [CrossRef]

46. Cabezas, H.; Bare, J.; Mallick, S. Pollution prevention with chemical process simulators: The generalized waste reduction (WAR) algorithm-Full version. Comput. Chem. Eng. 1999, 23, 623-634. [CrossRef]

47. Heijungs, R.H.G.; Lankreijer, R.; de Hayes, H.U.; Wegenersleeswijk, A. Environmental Life Cycle Assessment of Products Guide. Leiden: Centre of Environmental Science; CML: Leiden, The Netherlands, 1992.

48. Gangadharan, P.; Kanchi, K.; Lou, H. Evaluation of the economic and environmental impact of combining dry reforming. Chem. Eng. Res. Des. 2012. [CrossRef]

49. Kay, K.; Yasir, S. Biodiesel Production from Low Quality Crude Jatropha Oil Using Heterogeneous Catalyst. APCBEE Procedia 2012, 3, 23-27. [CrossRef]

50. Machado, G.; de Souza, T.; Aranda, D.; Pessoa, F.; Castier, M.; Cabral, V.; Cardozo-Filho, L. Computer simulation of biodiesel production by hydro-esterification. Chem. Eng. Process. Process Intensif. 2016, 103, 37-45. [CrossRef]

51. Yang, F.; Hanna, M.; Sun, R. Value-added uses for crude glycerol-A byproduct of biodiesel production. Biotechnol. Biofuels 2012. [CrossRef] [PubMed]

52. Environmental Protection Agency. Photochemical Smog-What It Means for Us; EPA Information; Environmental Protection Agency: South Austrialia, Australia, 2004.

53. Vallero, D. Fundamentals of Air Pollution, 5th ed.; Elsevier: Boston, MA, USA, 2014.

(C) 2018 by the authors. Licensee MDPI, Basel, Switzerland. This article is an open access article distributed under the terms and conditions of the Creative Commons Attribution (CC BY) license (http://creativecommons.org/licenses/by/4.0/). 